\title{
The evidence for radial artery grafting: When and when not?
}

Gianmarco Cancelli, MD, Katia Audisio, MD, David Chadow, MD, Giovanni J. Soletti, MD, and Mario Gaudino, MD, PhD

More than 18 million adults in the United States have coronary artery disease (CAD), accounting for $7 \%$ of the entire American adult population. ${ }^{1}$ Coronary artery bypass grafting (CABG) is the most performed type of cardiac surgery with about 370,000 cases annually in the United States. ${ }^{2}$

The first ever left internal thoracic artery (LITA) to left anterior descending anastomosis took place in 1968, performed by George Green in New York. Today this procedure has become the gold standard and the patency of this anastomosis correlates most strongly with improved outcomes and better survival. ${ }^{3}$

Just few years later, in 1973, Carpentier and colleagues ${ }^{4}$ first described the radial artery (RA) as a conduit for CABG. However, he subsequently advised against its use because of a higher rate $(35 \%)$ of occlusion or narrowing possibly attributed to spasm. ${ }^{5}$ Therefore, this graft quickly fell out of favor and would not be used again for approximately 20 years. In 1992, Acar and colleagues ${ }^{6}$ demonstrated that occluded or narrowed RA from the first Carpentier series were patent at 18 -year follow-up. Furthermore, he studied 122 RA grafts and showed that the early patency was $100 \%$, proving the RA was in fact suitable as a graft in CABG. ${ }^{6}$ Since then, the use of the RA has continued to increase for the treatment of patients with multivessel CAD undergoing CABG. Atraumatic harvesting technique, careful selection of the target vessel, and use of antispastic protocols are the likely reasons for the improved results of RA grafting in the cotemporary era.

\section{EVIDENCE OF SUPERIORITY OF THE RA OVER THE SAPHENOUS VEIN FOR CABG}

There are multiple options for choosing the second graft when performing $\mathrm{CABG}$ procedures in patients who require multiple bypass grafting. RA and saphenous vein (SV) are 2 of the most common conduits used along with the right internal thoracic artery (RITA). Multiple randomized clinical

From the Department of Cardiothoracic Surgery, Weill Cornell Medicine, New York, NY.

Received for publication July 29, 2021; accepted for publication Sept 20, 2021; available ahead of print Sept 24, 2021

Address for reprints: Mario Gaudino, MD, PhD, Department of Cardiothoracic Surgery, Weill Cornell Medicine, 525 E 68th St, New York, NY 10065 (E-mail: mfg9004@med.cornell.edu).

JTCVS Techniques 2021;10:114-9

2666-2507

Copyright (C 2021 The Author(s). Published by Elsevier Inc. on behalf of The American Association for Thoracic Surgery. This is an open access article under the CC BY-NC-ND license (http://creativecommons.org/licenses/by-nc-nd/4.0/).

https://doi.org/10.1016/j.xjtc.2021.09.039
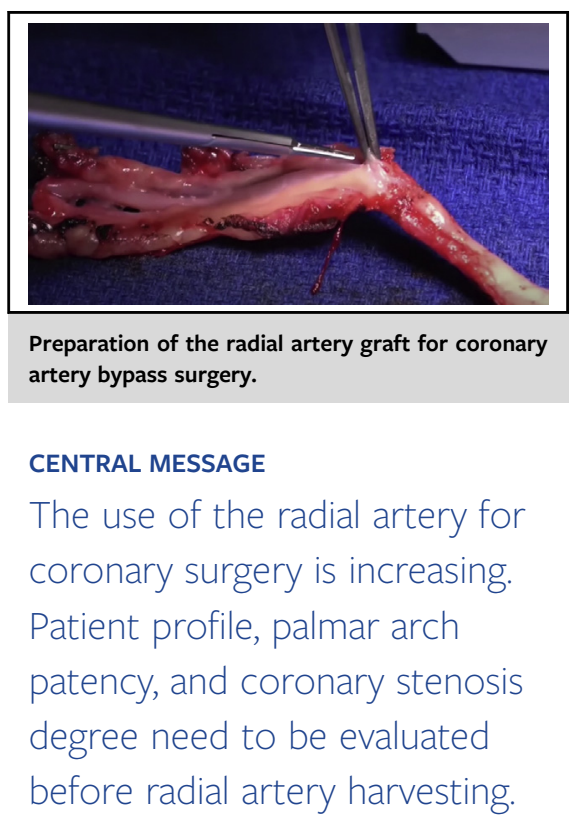

See Commentary on page 120.

trials and meta-analyses along with observational studies have demonstrated the superiority of the RA over the SV when it comes to graft patency and clinical outcomes (Table 1). ${ }^{7-11}$ A network meta-analysis including 3651 grafts showed that among all the conduits used for CABG, the RA was the best conduit in terms of patency at 5 -year follow-up (incidence rate ratio, $0.54 ; 95 \%$ confidence interval $[\mathrm{CI}], 0.35-0.82)^{7}$ A second meta-analysis of 14 studies and around 21,000 patients found decreased long-term mortality (incidence rate ratio, $0.74 ; 95 \% \mathrm{CI}$, $0.63-0.87 ; P<.001)$ in the RA group when compared with the SV group at 6.6 years of follow-up. The survival benefit was found to be independent of age, sex, diabetes status, and ventricular function. ${ }^{8}$ In the Radial Artery Database International Alliance, a patient-level meta-analysis including more than 1000 patients found lower risk of graft occlusion (hazard ratio [HR], 0.44; 95\% CI, 0.28-0.70) along with decreased incidence of adverse cardiac events (HR, 0.67; 95\% CI, 0.49-0.90) in the RA group compared with the SV group at 5 years of follow-up. ${ }^{9}$ In a subsequent report from the same database with 10-year follow-up, we found that patients who received the RA had also a lower incidence of the composite of death and myocardial infarction (HR, 0.77; 95\% CI, 0.63-0.94), and a higher survival 
TABLE 1. Summary of the main studies comparing radial artery (RA) with saphenous vein (SV) grafts in coronary artery bypass grafting

\begin{tabular}{|c|c|c|c|c|}
\hline Study & Study period & No. of patients & Follow-up (y) & Main findings \\
\hline Gaudino, $2021^{7}$ & $1993-2014$ & 3396 & 5 & $\begin{array}{l}\text { - The RA ranked as the best conduit (rank score for RA } 0.87 \text { vs } 0.85 \text { for no- } \\
\text { touch SV, } 0.23 \text { for RITA, } 0.29 \text { for GEA, and } 0.25 \text { for the conventionally } \\
\text { harvested SV). } \\
\text { - Compared with the conventionally harvested SV, only RA (IRR, } 0.54 \text {; } \\
95 \% \text { CI, } 0.35-0.82 \text { ) and no-touch SV (IRR, } 0.55 \text {; } 95 \% \text { CI, } 0.39-0.78 \text { ) } \\
\text { were associated with significantly lower rate of graft occlusion, whereas } \\
\text { RITA (IRR, } 1.02 ; 95 \% \text { CI, } 0.63-1.65 \text { ) and GEA (IRR, } 0.98 ; 95 \% \text { CI, } 0.57- \\
\text { 1.68) were not. }\end{array}$ \\
\hline Gaudino, $2019^{8}$ & $1993-2012$ & 20,931 & 7 & $\begin{array}{l}\text { - Long-term mortality was } 24.5 \% \text { in the RA group vs } 34.2 \% \text { in the SV } \\
\text { group (IRR, } 0.74 ; 95 \% \text { CI,: } 0.63-0.87 \text { ). At meta-regression, RA survival } \\
\text { benefit was independent of age, sex, diabetes status, and ventricular } \\
\text { function. }\end{array}$ \\
\hline Gaudino, $2018^{9}$ & 1996-2009 & 1036 & 5 & $\begin{array}{l}\text { - Compared with the SV group, the incidence of adverse cardiac events was } \\
\text { significantly lower in the RA group (HR, 0.67; 95\% CI, 0.49-0.90). } \\
\text { - Risk of occlusion (HR, 0.44; 95\% CI, 0.28-0.70), incidence of myocardial } \\
\text { infarction (HR, 0.72; 95\% CI, 0.53-0.99), and repeat revascularization } \\
\text { (HR, } 0.50 ; 95 \% \text { CI, 0.40-0.63) were also lower in the RA group. }\end{array}$ \\
\hline $\begin{array}{l}\text { Gaudino, } \\
2020^{10}\end{array}$ & 1997-2009 & 1036 & 10 & $\begin{array}{l}\text { - RA was associated with a significantly lower incidence of death, } \\
\text { myocardial infarction, or repeat revascularization when compared with } \\
\text { SV (HR, } 0.73 ; 95 \% \mathrm{CI}, 0.61-0.88 \text { ). } \\
\text { - RA was also associated with a significantly lower incidence of death or } \\
\text { myocardial infarction (HR, } 0.77 ; 95 \% \mathrm{CI}, 0.63-0.94 \text { ) and with a higher } \\
\text { survival rate (HR, } 0.73 ; 95 \% \mathrm{CI}, 0.57-0.93 \text { ) when compared with SV. } \\
\text { - The incidence of repeat revascularization was } 63 \text { events in the RA group } \\
\text { and } 86 \text { events in the SV group (HR, } 0.62 ; 95 \% \mathrm{CI}, 0.45-0.86 \text { ). }\end{array}$ \\
\hline Buxton, $2020^{11}$ & $1996-2005$ & 416 & 10 & $\begin{array}{l}\text { - In the RA vs SV comparison, the } 10 \text {-y patency was } 85 \% \text { for the RA and } \\
71 \% \text { for the SV (HR, } 0.40 ; 95 \% \text { CI, } 0.15-1.00 \text { ). The } 10 \text {-y survival was } \\
72.6 \% \text { in the RA group and } 65.2 \% \text { in the SV group (HR, } 0.76 ; 95 \% \text { CI, } \\
0.47-1.22 \text { ). } \\
\text { - In the RA vs RITA comparison, } 10 \text {-y patency was } 89 \% \text { for RA and } 80 \% \\
\text { for free RITA (HR, } 0.45 ; 95 \% \text { CI, } 0.23-0.88 \text { ). The } 10 \text {-y survival was } \\
90.9 \% \text { in the RA group and } 83.7 \% \text { in the RITA group (HR, } 0.53 ; 95 \% \mathrm{CI} \text {, } \\
0.30-0.95 \text { ). }\end{array}$ \\
\hline
\end{tabular}

RITA, Right internal thoracic artery; GEA, gastroepiploic artery; $I R R$, incidence rate ratio; $C I$, confidence interval; $H R$, hazard ratio.

rate (HR, 0.73; 95\% CI, 0.57-0.93). ${ }^{10}$ The Radial Artery Patency and Clinical Outcomes trial compared RITA versus RA in 394 patients and SV versus RA in 225 patients. In the RITA versus RA arm, the 10-year patency rate was $89 \%$ for RA versus $80 \%$ for RITA (HR, $0.45 ; 95 \%$ CI, $0.23-0.88$ ) and the survival estimate was $90.9 \%$ versus $83.7 \%$, respectively (HR, 0.53; 95\% CI, 0.30-0.95). In the SV versus RA arm, the patency rates were $85 \%$ for RA and $71 \%$ for SV (HR, 0.40; 95\% CI, 0.15-1.00) and 10-year survival estimate was $72.6 \%$ and $65.2 \%$, respectively (HR, 0.76 ; $95 \%$ CI, 0.47-1.22). ${ }^{11}$

Based on this findings, the 2018 European Society of Cardiology and European Association for CardioThoracic Surgery guidelines on myocardial revascularization conferred a Class I recommendation to the use of the $\mathrm{RA}$ for $\mathrm{CABG}{ }^{12}$ Because the evidence in support of the RA continues to grow stronger and stronger, it seems likely that when the new American College of Cardiology/American Heart Association guideline for myocardial revascularization will be published, the RA will have the same class of recommendation.

\section{HOW TO HARVEST THE RA}

There are 2 main techniques used for harvesting the RA: open radial artery harvesting technique (ORAH) and endoscopic RA harvesting (ERAH). Until the early 2000s the only way to harvest the RA was ORAH, which requires a 15 to $18 \mathrm{~cm}$ incision in the patient's forearm (Figure 1). It wasn't until 2000 with the creation of the endoscopic vessel harvesting system that ERAH was possible. Using the ERAH technique, a 2 to $3 \mathrm{~cm}$ incision just above the radial styloid prominence is all that is necessary. ${ }^{13}$

With the advancement in training and technologies, the endoscopic approach to harvest the RA for CABG 


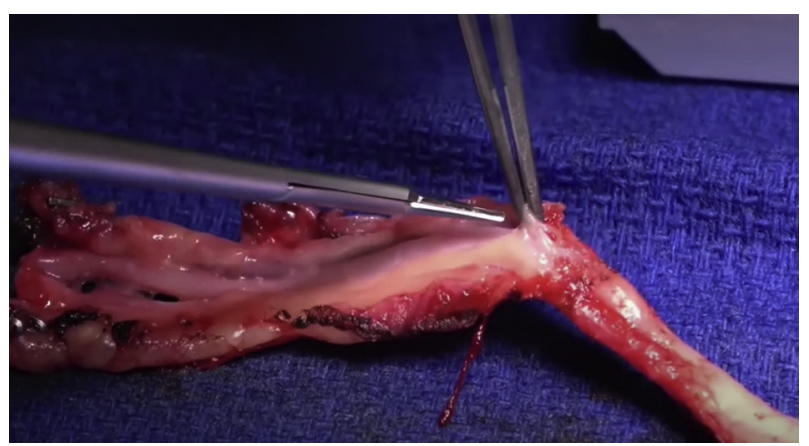

FIGURE 1. Preparation of the radial artery graft for coronary artery bypass surgery.

continues to grow in popularity. In an analysis of the Society of Thoracic Surgeons National Database from 2008 to 2018 we found that $43.2 \%$ of surgeons use ERAH and $56.8 \%$ ORAH (unpublished data). ${ }^{14}$

The concern with ERAH is that it requires more manipulation of the artery than ORAH, with higher risk of mechanical injury particularly to the endothelium. Damage to the RA endothelium during ERAH may lead to graft spasm, thrombosis, and occlusion and potentially put patients at higher risk of cardiac events. ${ }^{15}$ In vitro studies comparing RA endothelial integrity and function between the 2 techniques have provided discordant results. Older studies have reported no difference between the 2 techniques. ${ }^{16}$ However, in a more contemporary organ bath study, our group showed that ORAH is associated with better preservation of endothelial function compared with ERAH. ${ }^{17}$

On the other hand, multiple studies have showed that ERAH produces significantly less arm complications compared with ORAH. Rates of wound infection, postoperative pain, neuropathy, and hematoma have all been demonstrated to be significantly lower with ERAH. ${ }^{18-23} \mathrm{~A}$ meta-analysis of 4 small randomized controlled trials and 2 propensity-matched studies (743 patients; 324 ERAH) found that ERAH was associated with a lower incidence of wound complications (odds ratio, 0.33 ; $95 \%$ CI, 0.140.771 ), without significant difference in 30-day mortality, long-term mortality, and RA patency rate when compared with ORAH. ${ }^{20}$ Similar results were showed by Huang and colleagues $^{22}$ in a recent meta-analysis of 24 studies (15 observational, 12 of them unadjusted). ${ }^{22}$

The main conclusion is that the available evidence suggests that ERAH may have improved arm outcomes with no significant differences in clinical outcome or RA patency. ${ }^{15,22}$ However, most of the published studies are underpowered or are observational studies with biases in patient selection. Further randomized trials are needed to better understand the differences in outcomes between the 2 techniques.

\section{PREVENTING VASOSPASM OF THE RA}

Due to the predominantly muscular wall of the RA and the consequent concerns of spasm, antispastic therapy with calcium-channel blockers (CCBs) is generally used postoperatively in patients with RA grafts. A survey of all Canadian cardiac surgery centers reported that some form of antispastic therapy is adopted in almost all institutions (25 out of 27) after RA grafting. ${ }^{24}$ However, the published evidence on the effect of CCB on the RA is controversial. In a small randomized trial, our group assigned 120 patients who received the RA for CABG to continue or suspend the CCBs after the first postoperative year and found no difference in graft patency, graft reactivity, myocardial ischemia, or clinical outcomes at 5-year follow-up. ${ }^{25}$ Subsequently, in another small trial, we randomized 100 patients to receive or not receive CCBs from the early postoperative period and did not find a difference in clinical and angiographic outcomes at 1 year. ${ }^{26}$ In a post hoc analysis of the Radial Artery Patency Study, among 440 RA patients, the incidence of string sign (the highest degree of RA graft spasm) was not influenced by the compliance with the prescribed postoperative CCBs. ${ }^{27}$ On the other hand, in a post hoc analysis of data in the Radial Artery Database International Alliance including 732 patients, we found that CCB therapy was associated with a significantly lower risk of major adverse cardiac events (HR, 0.52; 95\% CI, $0.31-0.89$ ) and RA graft occlusion (HR, $0.20 ; 95 \% \mathrm{CI}$, $0.08-0.49) .{ }^{28}$ This post hoc analysis shares the limitations of observational studies, especially in terms of indication biases and unmeasured confounders ${ }^{29}$ because it is likely that healthier patients were more compliant with the CCB therapy. Due to the lack of clear data supporting the use of CCBs following RA grafting, further randomized studies are necessary to better understand the real influence of CCBs on the RA grafting.

\section{WHEN AND WHEN NOT TO USE THE RA}

The key reasons not to use the RA are insufficient ulnar artery compensation to RA removal or contraindications to harvesting (Table 2). The latter includes history of major arm trauma or surgery, vasculitis, or Raynaud syndrome. ${ }^{30}$ Some autoimmune conditions, including scleroderma and rheumatoid arthritis, are also contraindications. ${ }^{31}$ Additionally, RA harvesting is contraindicated in patients who have advanced chronic kidney disease and are at risk for future dialysis because the RA may be needed for dialysis access. ${ }^{30}$ Furthermore, patients who have undergone coronary angiography via RA access should not have RA harvesting. ${ }^{30}$

The adequacy of ulnar compensation to RA removal must be carefully assessed before harvesting. The clinical Allen's test (AT) alone is not sufficient. Patients can have a normal AT but an incomplete arch, as shown by Agrifoglio and 
TABLE 2. Contraindications to the use of radial artery (RA) as a conduit for coronary artery bypass grafting

\begin{tabular}{l} 
When not to use RA \\
History of major arm trauma \\
Prior surgery on the arm \\
Vasculitis \\
Raynaud syndrome \\
Scleroderma \\
Advanced chronic kidney disease \\
Dialysis \\
Angiography via RA access \\
Insufficient ulnar artery compensation, evaluated with Allen test, Barbeau test, echo-Doppler, Doppler plethysmography \\
Mild-to-moderate stenosis of the coronary target vessel, evaluated with visual inspection, quantitative coronary angiography, fractional flow reserve \\
\hline
\end{tabular}

colleagues, where 8 out of 150 patients had incomplete arches despite a normal AT. ${ }^{32}$ Therefore, a second test should be done if the AT is normal. Among the simplest confirmatory tests is the Barbeau test, in which a pulse oximeter is placed on the index finger and both the ulnar artery and RA are manually occluded. Complete occlusion is confirmed by lack of a waveform on the pulse oximeter. The ulnar artery is then released; if the palmar arch is incomplete, the pulse oximeter waveform does not come back. $^{33}$ Another option is echo-Doppler evaluation that can also determine the vessel size and identify plaques or calcifications. Patients are eligible for RA grafting if the vessel has a diameter $>2.0 \mathrm{~mm}$, with minimal evidence of plaque or calcifications. Other valuable information provided by Doppler ultrasound include the shape of the RA waveform and the evaluation of the ulnar collateral blood supply during manual compression of the RA. ${ }^{34,35}$ Doppler plethysmography assesses the palmar arch by visualization of pulsatile waveforms in each of the digits before and after RA compression. If the waveforms are either marginal or absent at baseline or after RA compression, the RA should not be used. ${ }^{36}$ Other modalities such as computed tomography angiography, and intraoperative RA pressure measurement are less commonly used. ${ }^{37}$ The RA should be harvested from the arm with the best ulnar compensation, without concerns related to hand dominance.

A third key reason not to use the RA is related to the coronary target vessel. The RA has a more muscular wall than RITA and LITA and SV and as such is more prone to spasm in case of mild-to-moderate coronary stenosis and chronic competitive flow. ${ }^{38}$ If the target vessel has mild or moderate stenosis, a greater shear force produced by the oscillating flow between the conduit and native circulations may impair endothelial function predisposing to an anastomotic occlusion. ${ }^{39}$ In an analysis of 123 postoperative angiographies, the RA patency rate for target vessel with moderate stenosis $(50 \%$ to $74 \%)$ was $78.9 \%$ compared with $84.9 \%$ for severe stenosis $(75 \%$ to $89 \%)$ and $98 \%$ for critical stenosis $(\geq 90 \%)(P=.001)$. At multivariable analysis, anastomosis to a vessel with stenosis $<90 \%$ was an independent predictor of graft occlusion (HR, $14.9 ; 95 \% \mathrm{CI}, 2.6-83.2){ }^{40}$
Furthermore, in an angiographic evaluations of RA grafts after 20 years of follow-up, we found a patency rate of the RA similar to that of LITA when anastomosed to target vessels with stenosis $\geq 90 \%{ }^{41}$

Visual inspection, quantitative coronary angiography, and fractional flow reserve (FFR) have all been used to estimate the severity of the coronary stenosis and the potential for competitive flow. It is important to note that target vessel stenosis is a relatively inaccurate surrogate for chronic competitive flow because it does not account for the minimal residual lumen diameter or the functional assessment of the stenosis, which may be better indicators of chronic competitive flow. FFR is the only direct method to assess the hemodynamic effect of a stenosis. Based on the most recent evidence, a FFR cutoff of less than 0.75 to 0.80 is used to distinguish functionally and nonfunctionally significant stenosis. ${ }^{42}$ In the Impact of Preoperative FFR on Arterial Bypass Graft Function trial, Glineur and colleagues ${ }^{43}$ found a significant association between the preoperative FFR measurement of the target vessel and the anastomotic functionality at 6 months $(P<.001)$, with a cutoff of $0.78 .^{43}$ It must be noted that the majority of grafts in are LITA or RITA, not RA. In an analysis of 164 patients, Botman and colleagues $^{44}$ found a graft occlusion rate of $8.9 \%$ when FFR was $>0.75$ and $21.4 \%$ when FFR was $<0.75$ $(P<.001)$. We have been using the ratio between the diameter of the RA and the diameter of the target vessel for decision making, with a cutoff of 1.3.

The RA can be proximally anastomosed to the ascending aorta or to the LITA and RITA. It seems that when RA is proximally anastomosed to the ascending aorta, the higher pressure in the aorta helps with eventual competitive flow, whereas the anastomosis with the ITAs makes the RA more vulnerable to the negative effect of chronic native competitive flow. In an analysis of 228 consecutive, the use of ITA-anastomosed RA, compared with aorta-anastomosed RA, was associated with higher rate of graft failure when the coronary target vessel had a $70 \%$ to $90 \%$ stenosis $(25.0 \%$ vs $2.4 \% ; P=.02)$. No difference was found when the coronary stenoses were $>90 \%{ }^{45}$ 
With the exception of the higher risk of failure of ITA anastomosed RA grafts in situations of competitive flow, there are no data to support difference in patency rate of RA grafts based on target vessels location or graft configuration.

\section{CONCLUSIONS}

The RA has been showed to be superior to the SV in CABG and its use is increasing for the treatment of patients with multivessel CAD undergoing CABG. Patient profile, patency of the palmar arch, and stenosis of the target vessel must be considered in the decision-making process to use the RA, but in principle the conduit should be used every time it is not contraindicated. The optimal technique for harvesting the RA and the use of CCBs need further evaluation.

\section{Conflict of Interest Statement}

The authors reported no conflicts of interest.

The Journal policy requires editors and reviewers to disclose conflicts of interest and to decline handling or reviewing manuscripts for which they may have a conflict of interest. The editors and reviewers of this article have no conflicts of interest.

\section{References}

1. Fryar CD. Prevalence of uncontrolled risk factors for cardiovascular disease: United States, 1999-2010. NCHS Data Brief. 2012;103:1-8.

2. Benjamin EJ, Muntner P, Alonso A, Bittencourt MS, Callaway CW, Carson AP, et al. Heart disease and stroke statistics-2019 update: a report from the American Heart Association. Circulation. 2019;139:e56-528.

3. Green GE, Stertzer SH, Reppert EH. Coronary arterial bypass grafts. Ann Thorac Surg. 1968:5:443-50.

4. Carpentier A, Guermonprez JL, Deloche A, Frechette C, DuBost C. The aorta-tocoronary radial artery bypass graft: a technique avoiding pathological changes in grafts. Ann Thorac Surg. 1973;16:111-21.

5. Carpentier A, Geha AS, Krone RJ, McCormick JR, Baue AE. Selection of coronary bypass: anatomic, physiological, and angiographic considerations of vein and mammary artery grafts. J Thorac Cardiovasc Surg. 1975;70:414-31.

6. Acar C, Jebara VA, Portoghese M, Beyssen B, Pagny JY, Grare P, et al. Revival of the radial artery for coronary artery bypass grafting. Ann Thorac Surg. 1992;54: 652-9.

7. Gaudino M, Hameed I, Robinson NB, Ruan Y, Rahouma M, Naik A, et al. Angiographic patency of coronary artery bypass conduits: a network meta-analysis of randomized trials. J Am Heart Assoc. 2021;10:e019206.

8. Gaudino M, Rahouma M, Abouarab A, Leonard J, Kamel M, Di Franco A, et al. Radial artery versus saphenous vein as the second conduit for coronary artery bypass surgery: a meta-analysis. J Thorac Cardiovasc Surg. 2019;157:1819-25.

9. Gaudino M, Benedetto U, Fremes S, Biondi-Zoccai G, Sedrakyan A, Puskas JD, et al. Radial-artery or saphenous-vein grafts in coronary-artery bypass surgery. $N$ Engl J Med. 2018;378:2069-77.

10. Gaudino M, Benedetto U, Fremes S, Ballman K, Biondi-Zoccai G, Sedrakyan A, et al. Association of radial artery graft vs saphenous vein graft with long-term cardiovascular outcomes among patients undergoing coronary artery bypass grafting: a systematic review and meta-analysis. JAMA. 2020;324:179-87.

11. Buxton BF, Hayward PA, Raman J, Moten SC, Rosalion A, Gordon I, et al. Longterm results of the RAPCO trials. Circulation. 2020;142:1330-8.

12. Sousa-Uva M, Neumann F-J, Ahlsson A, Alfonso F, Banning AP, Benedetto U, et al. 2018 ESC/EACTS guidelines on myocardial revascularization. Eur J Cardiothorac Surg. 2019;55:4-90.

13. Blitz A, Osterday RM, Brodman RF. Harvesting the radial artery. Ann Cardiothorac Surg. 2013;2:533-42.
14. Gaudino M, Rahouma M, Habib RH, Hameed I, Robinson NB, Farrington WJ, et al. Surgeons' coronary bypass practice patterns in the United States. J Am Coll Cardiol. 2020;76:1714-5.

15. Kinlay S, Libby P, Ganz P. Endothelial function and coronary artery disease. Curr Opin Lipidol. 2001;12:383-9.

16. Shapira OM, Eskenazi BR, Anter E, Joseph L, Christensen TG, Hunter CT, et al. Endoscopic versus conventional radial artery harvest for coronary artery bypass grafting: functional and histologic assessment of the conduit. $J$ Thorac Cardiovasc Surg. 2006;131:388-94.

17. Gaudino MF, Lorusso R, Ohmes LB, Narula N, McIntire P, Gargiulo A, et al Open radial artery harvesting better preserves endothelial function compared to the endoscopic approach. Interact Cardiovasc Thorac Surg. 2019;29:561-7.

18. Tamim M, Alexiou C, Al-Hassan D, Al-Faraidy K. Prospective randomized trial of endoscopic vs open radial artery harvest for $\mathrm{CABG}$ : clinical outcome, patient satisfaction, and midterm RA graft patency. J Card Surg. 2020;35:2147-54.

19. Kiaii BB, Swinamer SA, Fox SA. A prospective randomized study of endoscopic versus conventional harvesting of the radial artery. Innovations. 2017;12:231-8.

20. Rahouma M, Kamel M, Benedetto U, Ohmes LB, Franco AD, Lau C, et al. Endoscopic versus open radial artery harvesting: a meta-analysis of randomized controlled and propensity matched studies. J Card Surg. 2017;32:334-41.

21. Cao C, Tian DH, Ang SC, Peeceeyen S, Allan J, Fu B, et al. A meta-analysis of endoscopic versus conventional open radial artery harvesting for coronary artery bypass graft surgery. Innovations. 2014;9:269-75.

22. Huang T-Y, Huang T-S, Cheng Y-T, Wang Y-C, Chen T-P, Yin S-Y, et al. Radial artery harvesting in coronary artery bypass grafting surgery — endoscopic or open method? A meta-analysis. PLoS One. 2020;15:e0236499.

23. Dimitrova KR, Hoffman DM, Geller CM, DeCastro H. Endoscopic radial artery harvest produces equivalent and excellent midterm patency compared with open harvest. Innovations. 2010;5:265-9.

24. Myers MG, Fremes SE. Prevention of radial artery graft spasm: a survey of Canadian surgical centres. Can J Cardiol. 2003;19:677-81.

25. Gaudino M, Glieca F, Luciani N, Alessandrini F, Possati G. Clinical and angiographic effects of chronic calcium channel blocker therapy continued beyond first postoperative year in patients with radial artery grafts: results of a prospective randomized investigation. Circulation. 2001;104:164-7.

26. Gaudino M, Luciani N, Nasso G, Salica A, Canosa C, Possati G. Is postoperative calcium channel blocker therapy needed in patients with radial artery grafts? $J$ Thorac Cardiovasc Surg. 2005; 129:532-5.

27. Miwa S, Desai N, Koyama T, Chan E, Cohen EA, Fremes SE, et al. Radial artery angiographic string sign: clinical consequences and the role of pharmacologic therapy. Ann Thorac Surg. 2006;81:112-8.

28. Gaudino M, Benedetto U, Fremes SE, Hare DL, Hayward P, Moat N, et al. Effect of calcium-channel blocker therapy on radial artery grafts after coronary bypass surgery. J Am Coll Cardiol. 2019;73:2299-306.

29. Gaudino M, Di Franco A, Rahouma M, Tam DY, Iannaccone M, Deb S, et al. Unmeasured confounders in observational studies comparing bilateral versus single internal thoracic artery for coronary artery bypass grafting: a meta-analysis. J Am Heart Assoc. 2018;7:e008010.

30. Gaudino M, Fremes S, Schwann TA, Tatoulis J, Wingo M, Tranbaugh RF. Technical aspects of the use of the radial artery in coronary artery bypass surgery. Ann Thorac Surg. 2019;108:613-22.

31. Budillon AM, Nicolini F, Agostinelli A, Beghi C, Pavesi G, Fragnito C, et al. Complications after radial artery harvesting for coronary artery bypass grafting: our experience. Surgery. 2003;133:283-7.

32. Agrifoglio M, Dainese L, Pasotti S, Galanti A, Cannata A, Roberto M, et al. Preoperative assessment of the radial artery for coronary artery bypass grafting: is the clinical Allen test adequate? Ann Thorac Surg. 2005;79:570-2.

33. Barbeau GR, Arsenault F, Dugas L, Simard S, Larivière MM. Evaluation of the ulnopalmar arterial arches with pulse oximetry and plethysmography: comparison with the Allen's test in 1010 patients. Am Heart J. 2004;147:489-93.

34. Jarvis MA, Jarvis CL, Jones PR, Spyt TJ. Reliability of Allen's test in selection of patients for radial artery harvest. Ann Thorac Surg. 2000;70:1362-5.

35. Pola P, Serricchio M, Flore R, Manasse E, Favuzzi A, Possati GF. Safe removal of the radial artery for myocardial revascularization: a Doppler study to prevent ischemic complications to the hand. J Thorac Cardiovasc Surg. 1996;112: 737-44.

36. Kohonen M, Teerenhovi O, Terho T, Laurikka J, Tarkka M. Is the Allen test reliable enough? Eur J Cardiothorac Surg. 2007;32:902-5.

37. Gaudino M, Crea F, Cammertoni F, Mazza A, Toesca A, Massetti M. Technical issues in the use of the radial artery as a coronary artery bypass conduit. Ann Thorac Surg. 2014;98:2247-54. 
38. van Son JA, Smedts F, Vincent JG, van Lier HJ, Kubat K. Comparative anatomic studies of various arterial conduits for myocardial revascularization. J Thorac Cardiovasc Surg. 1990;99:703-7.

39. Maniar HS, Sundt TM, Barner HB, Prasad SM, Peterson L, Absi T, et al. Effect of target stenosis and location on radial artery graft patency. J Thorac Cardiovasc Surg. 2002; 123:45-52.

40. Yie K, Na C-Y, Oh SS, Kim J-H, Shinn S-H, Seo H-J. Angiographic results of the radial artery graft patency according to the degree of native coronary stenosis. Eur J Cardiothorac Surg. 2008;33:341-8.

41. Gaudino M, Tondi P, Benedetto U, Milazzo V, Flore R, Glieca F, et al. Radial artery as a coronary artery bypass conduit: 20-year results. J Am Coll Cardiol. 2016;68:603-10.

42. Spadaccio C, Glineur D, Barbato E, Di Franco A, Oldroyd KG, Biondi-Zoccai G, et al. Fractional flow reserve-based coronary artery bypass surgery: current evidence and future directions. JACC Cardiovasc Interv. 2020;13:1086-96.
43. Glineur D, Grau JB, Etienne P-Y, Benedetto U, Fortier JH, Papadatos S, et al Impact of preoperative fractional flow reserve on arterial bypass graft anastomotic function: the IMPAG trial. Eur Heart J. 2019;40:2421-8.

44. Botman CJ, Schonberger J, Koolen S, Penn O, Botman H, Dib N, et al. Does stenosis severity of native vessels influence bypass graft patency? A prospective fractional flow reserve-guided study. Ann Thorac Surg. 2007;83: 2093-7.

45. Gaudino M, Alessandrini F, Pragliola C, Cellini C, Glieca F, Luciani N, et al. Effect of target artery location and severity of stenosis on mid-term patency of aorta-anastomosed vs. internal thoracic artery-anastomosed radial artery grafts. Eur J Cardiothorac Surg. 2004;25:424-8.

Key Words: coronary artery bypass surgery, radial artery, multiple arterial grafting, harvesting techniques 